WSRC-TR-92-375

\title{
CORROSION TESTS OF DWPF RECYCLE SOLUTION (U)
}

\author{
P. E. Zapp
}

WSRC-TR--92-375

DE93 012135

Heviewing
$\begin{aligned} & \text { official: } \\ & \text { Date: }\end{aligned} \quad 8 / 21 / 92$

Westinghouse Savannah River Company Savannah River Site

Aiken, SC 29808

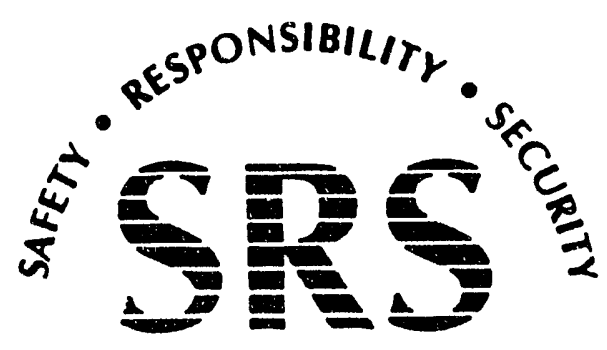


WSRC-TR-92-375

THIS PAGE INTENTIONALLY LEFT BLANK 


\section{CONTENTS}

SUMMARY

INTRODUCTION

EXPERIMENTAL PROCEDURE

RESULTS

Uniform Corrosion 3

Pitting 3

Deposits

CONCLUSIONS

FUTURE WORK

4

REFERENCES

5

TABLES

6

FIGURES 
WSRC-TR-92-173

\section{LIST OF TABLES}

\section{Page}

Table I Composition Of Aqueous Phase Of Coupon Test Solutions (ppm)

Table II Results Of Inspection Of Tested Coupons

\section{LIST OF FIGURES}

Figure 1. Uniform Corrosion On The Vapor Space Portion Of A537 Coupons Exposed To Solution 1.

Figure 2. Type 304L Stainless Steel Coupons After Immersion.

Figure 3. Liquid Mercury Drops And Particulate Deposits On An A537 8 Coupon (Magnification 65X). 


\section{APPROVALS}

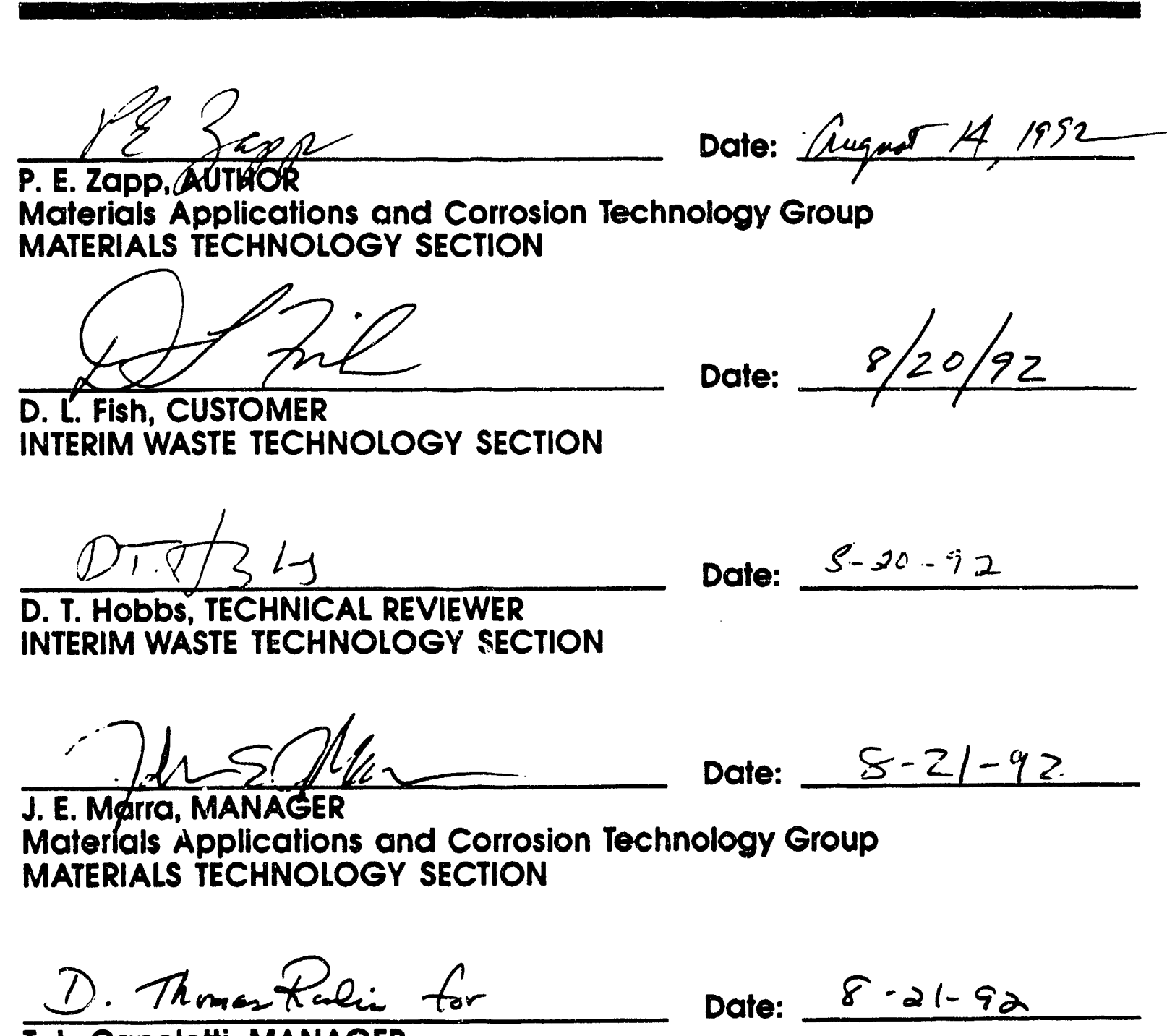

T. L. Capeletti, MANAGER MATERIALS TECHNOLOGY SECTION 
WSRC-TR-92-375

THIS PAGE INTENTIONALLY LEFT BLANK 


\section{CORROSION TESTS OF DWPF RECYCLE \\ SOLUTIONS (U) \\ Philip E. Zapp \\ Westinghouse Savannah River Company \\ Savannah River Site \\ Aiken, SC 29808}

\section{SUMMARY}

Coupon immersion tests were performed on ASTM A537, Class 1 carbon steel in simulated DWPF recycle solutions at $93 \pm 2^{\circ} \mathrm{C}$, in an effort to reproduce the results of earlier tests in which hard, shock-sensitive deposits were found. There was no evidence of pitting corrosion on the coupons exposed to solutions containing $0.5 \mathrm{M}$ hydroxide and $2000 \mathrm{ppm}(0.043 \mathrm{M})$ nitrite. Liquid mercury and small solid deposits were found on the specimens' immersed surfaces. However, the deposits were soft and not shock-sensitive. The absence of shock-sensitive deposits may have been due to a lower mercuric ion concentration in the test solutions or to different postimmersion handling. Coupons of 304L stainless steel and alloy C276 were also immersed in the simulated recycle solution. These coupons were not subject to localized corrosion, nor were shock-sensitive deposits found. Additional immersion tests on A537 coupons will be started in July, 1992.

\section{INTRODUCTION}

Contaminated waste water generated in the Defense Waste Processing Facility (DWPF) will be collected in the DWPF recycle collection tank (fabricated from alloy C276), where it will be made alkaline, and then pumped to Tank 43 in H-Area. Tank 43, a Type III waste tank, serves additionally as the $1 \mathrm{H}$ evaporator feed tank and a fresh canyon waste receipt tank. The alkaline recycle stream, amounting to several million gallons per year, will likely be the major input to tank 43 . Necessary corrosion inhibitors will be added to the recycle collection tank so that the recycle stream will neither be corrosive to tank 43 nor depend upon inhibitors already in that tank for protection.

Corrosion testing of waste tank steel, ASTM A537 class 1 carbon steel (A537), in simulated recycle solutions has been conducted since the since the mid-1980s, with the objective of establishing minimum concentrations of the hydroxide and nitrite corrosion inhibitors. Coupon immersion tests of susceptibility to general and localized corrosion were conducted by the DuPont Co. at the Engineering Test Center (ETC), Newark DE. ${ }^{1,2}$ Electrochemical tests for localized corrosion were conducted at SRS in 1988. ${ }^{3}$ The simulants used in both sets of tests were based conservatively on the recycle stream's originating entirely from DWPF melter off-gas concentrate, the most concentrated among the available sources. The composition of one particular simulant (identified as 'Matrix C' solution) thought to be the best estimate of the offgas concentrate is shown in Table 1. Tests using this simulant were conducted with varied levels of nitrite and hydroxide (and carbonate/bicarbonate in the electrochemical tests). 
In the ETC coupon tests, as-received, 600-grit polished A537 coupons were partially immersed in test solution for periods of one month and four months at temperatures of 70 and $90^{\circ} \mathrm{C}$. It was found that $1.7 \%$ hydroxide ( $1 \mathrm{M}$ hydroxide) combined with $0.2 \%$ nitrite inhibited pitting corrosion at $90^{\circ} \mathrm{C}$. Some slight $(<0.001$ in.) crevice corrosion was found with these inhibitor concentrations, and the overall general corrosion rate was determined to be approximately 0.0005 in. per year. At $0.85 \%$ hydroxide $(0.5 \mathrm{M})$ and $2000 \mathrm{ppm}$ nitrite crevice corrosion was observed. Slightly less crevice and general corrosion were seen on A537 coupons which had been presoaked in caustic or stress-relief heat-treated in air prior to immersion.

In the SRS electrochemical corrosion tests, cyclic potentiodynamic polarization scans were conducted at temperatures up to $80^{\circ} \mathrm{C}$. The hydroxide content in these tests was lowered from the ETC solution concentrations to a steady-state value representative of an aqueous film on the tank wall which is saturated with atmospheric carbon dioxide (which depletes hydroxide in the film faster than it can be replenished from the bulk solution). The results of these tests agreed with the ETC coupon results. Localized attack was absent in solutions with a steady-state $\mathrm{pH}$ of 10.18 (which results from an initial hydroxide concentration of $1.7 \%$ ) and with nitrite concentrations of $0.1 \%$ and $0.2 \%$.

In the course of the analyzing the four-month ETC coupon immersion tests, shocksensitive deposits were found at and below the liquid-air interface on the coupons, as well as on Teflon ${ }^{\mathrm{TM}}$ washers and string and type 316 stainless steel hardware attached to the coupons. ${ }^{4}$ Generally more deposits formed on the $90^{\circ} \mathrm{C}$ coupons than on the $70^{\circ} \mathrm{C}$ coupons. The deposits were 50 to $100 \mu \mathrm{m}$ in diameter and were determined to be a mercury-based compound, but to this date they have not been precisely characterized. Nor have the precise conditions under which the deposits form been established. The small quantity of deposits produced on the coupons has made analyses difficult.

The issue of shock-sensitive deposits remains important. This report describes coupon immersion tests conducted at SRTC in order to reproduce the findings of the earlier tests. The work was conducted as non-critical task (NRTSC) 91-079-0, "Corrosivity of DWPF Recycle Stream."

\section{EXPERIMENTAL PROCEDURE}

The coupons used in this study were fabricated from ASTM A537 class 1 carbon steel (A537), type 304L stainless steel (304L), or alloy C276 by Metal Samples, Inc., Munford, Ala. The 304L and C276 specimens were not expected to corrode in the recycle stream, but, as materials of construction in the inter-area transfer line and the recycle collection tank respectively, were tested for completeness. All but one set of specimens were tested with a 600-grit polished surface. A set of A537 specimens was tested with a mill scale surface. One set of three A537 polished coupons was heattreated in air for one hour at $1100^{\circ} \mathrm{F}$ to simulate the stress-relieving heat treatment applied to fabricated waste tanks. 
The A537 and 304L coupons were partially immersed (one half in liquid, one half in vapor) in test solution for four months to study the corrosion behavior of waste tank steel at and near the solution-air interface. The alloy C276 specimens were 0.62-in.diameter discs and were placed on the bottom of their solution bottle. Three coupons were suspended with Teflon ${ }^{\mathrm{TM}}$-coated copper wire in each of six one-liter Teflon ${ }^{\mathrm{TM}}$ bottles containing $500 \mathrm{~mL}$ of solution. The bottles were placed in a Blue M oven at $93 \pm$ $2^{\circ} \mathrm{C}$. Humidified air was injected into the vapor space of the bottles at $100 \mathrm{~mL} / \mathrm{min}$ to simulate the waste tank air flow. Distilled water was added to the bottles on alternate days to replace evaporated water. At the end of the exposure the coupons were removed, rinsed in distilled water, and microscopically examined for pitting corrosion and for solid deposits. The carbon steel coupons were then cleaned of corrosion products in Clarke's solution (complexed hydrochloric acid) and the stainless steel coupons in nitric acid for further pitting evaluation.

Two test solutions were made up from reagent grade chemicals and distilled water, according to the "Matrix $\mathrm{C}^{\text {" }}$ recipe used in the ETC tests. The solutions' ionic concentrations are shown in Table 1, along with post-immersion analytical results from three solution 1 bottles. Solutions 1 and 2 differed only in their nitrite concentrations, with $2000 \mathrm{ppm}$ in solution 1 and 300 in solution 2. All anions were added as sodium salts; nitrate was added also as mercuric nitrate.

\section{RESULTS}

\section{Uniform Corrosion}

Table II gives a summary of coupon surface conditions and corrosion results. All polished A537 coupons had patches of uniform corrosion on the vapor space portion of their surfaces (Figure 1). This corrosion was generally limited to the uppermost areas of the coupons and was absent from the steel both below and immediately above the solution-vapor interface. The coupon surfaces at and below the interface were relatively clean and uncorroded. There was no effect of nitrite concentration on the vapor space uniform corrosion. The location of the uniform corrosion suggests that it arose from the condensation of water which was evaporated from the solution or injected as vapor in the air purge. The deepest penetration measured was 0.005 in., which would yield a corrosion rate of 0.015 in./yr. This rate is much higher than the near-zero corrosion rate deduced from actual waste tank wall-thickness measurements. The difference is attributed to the condensate source of the corrosion and the nature of the polished specimen surface.

The rate measured in this study differs from that in the ETC tests $(0.0005 \mathrm{in} . / \mathrm{yr})$ because the latter rate was determined from weight loss measurements on specimens with similar patches of uniform corrosion. Corrosion rates which are calculated from weight loss average the corrosion over the entire specimen area, and thus yield a lower rate than do localized penetration values when the uniform corrosion covers a fraction of the specimen area. Weight loss was not measured in the present study. 
There was also a uniform corrosion of the stainless steel coupons in the form of a gray and brown tarnish on portions of the liquid-immersed surfaces (Figure 2). The alloy C276 discs, which were submerged in test solution, were only lightly stained with a yellowish residue.

\section{Pitting}

The objective of these tests is to determine whether a solution does or does not inhibit pitting. Pitting corrosion under near-inhibiting conditions is frequently shallow in depth and small in diameter. It is typically determined by optical microscopy at magnifications up to 70X. The minimum depth of attack which can be distinguished from non-pit surface flaws is about $0.001 \mathrm{in}$. Pits usually are surrounded by an uncorroded (cathodic) area, which sets off the pit from a non-pit flaw and provides corroboration of the pitting assessment.

Pitting attack was found only on one A537 coupon exposed to the low nitrite (300 ppm) solution. A pit developed at about $0.7 \mathrm{in}$. above the solution-vapor interface and had a depth of $0.001 \mathrm{in}$. Pitting was not found on the high-nitrite-solution carbon steel coupons or on the $304 \mathrm{~L}$ or C 276 specimens.

\section{Deposits}

Solid particulate deposits were observed on wetted surfaces of the $304 \mathrm{~L}$ and polished A537 coupons. The deposits were smaller (1 - 2 mils across), and on the carbon steel, less numerous compared with those reported in the ETC tests. These deposits were not shock-sensitive, as determined by mechanical probing with a dissecting needle. Liquid mercury drops were also observed on the A537 and 304L coupons. Mercuric ion in the test solution is reduced in a cathodic reaction associated with corrosion. The mercuric ion in solution at the end of the immersions ranged from 20 to $43 \mathrm{ppm}$. These values are lower than the 70 to $90 \mathrm{ppm}$ reported in the ETC tests. Figure 3 shows liquid mercury drops and particulate deposits on an A537 coupon exposed to solution 1 .

\section{CONCLUSIONS}

Pitting is inhibited on A537 carbon steel in the $0.5 \mathrm{M}$-hydroxide recycle simulant when $2000 \mathrm{ppm}$ nitrite are present. Slight pitting was observed when the nitrite concentration was $300 \mathrm{ppm}$. Shock-sensitive deposits were not found on any coupons in this study. Some of the ETC coupons were evidently dried in air at $60^{\circ} \mathrm{C}$ after testing. This step, not followed in the present tests, may have contributed to the development of the shock-sensitive compound.

\section{FUTURE WORK}

Additional coupon tests in solutions with the same recipe will be run beginning in July, 1992. A new constant temperature apparatus will be used in place of the Blue $M$ 
oven. The test bottles will be equipped with reflux condensers to maintain a constant liquid level and to reduce the frequency of distilled water additions. Some coupons will be dried at $60^{\circ} \mathrm{C}$ in air to reproduce the drying step in the ETC tests.

\section{REFERENCES}

1. M. K. Carlson, "Materials of Construction Composite Group Meeting," March 6 and 7, 1989 (U), ${ }^{n}$ OPS-WMQ-89-0057, June 23, 1989.

2. J. J. Kvochak to R. Eibling, "Corrosion Testing - Impact Sensitive Deposits," March 3, 1989.

3. J. D. Fritz, "Inhibitor Requirements for the DWPF Recycle Solution," DPST-88-863, September 22, 1988.

4. J. J. Kvochak to M. K. Carlson, “ Corrosion Testing - Tank Farm Recycle Solutions," June 16, 1988. 
TABLE I. Composition Of Aqueous Phase Of Coupon Test Solutions (ppm)

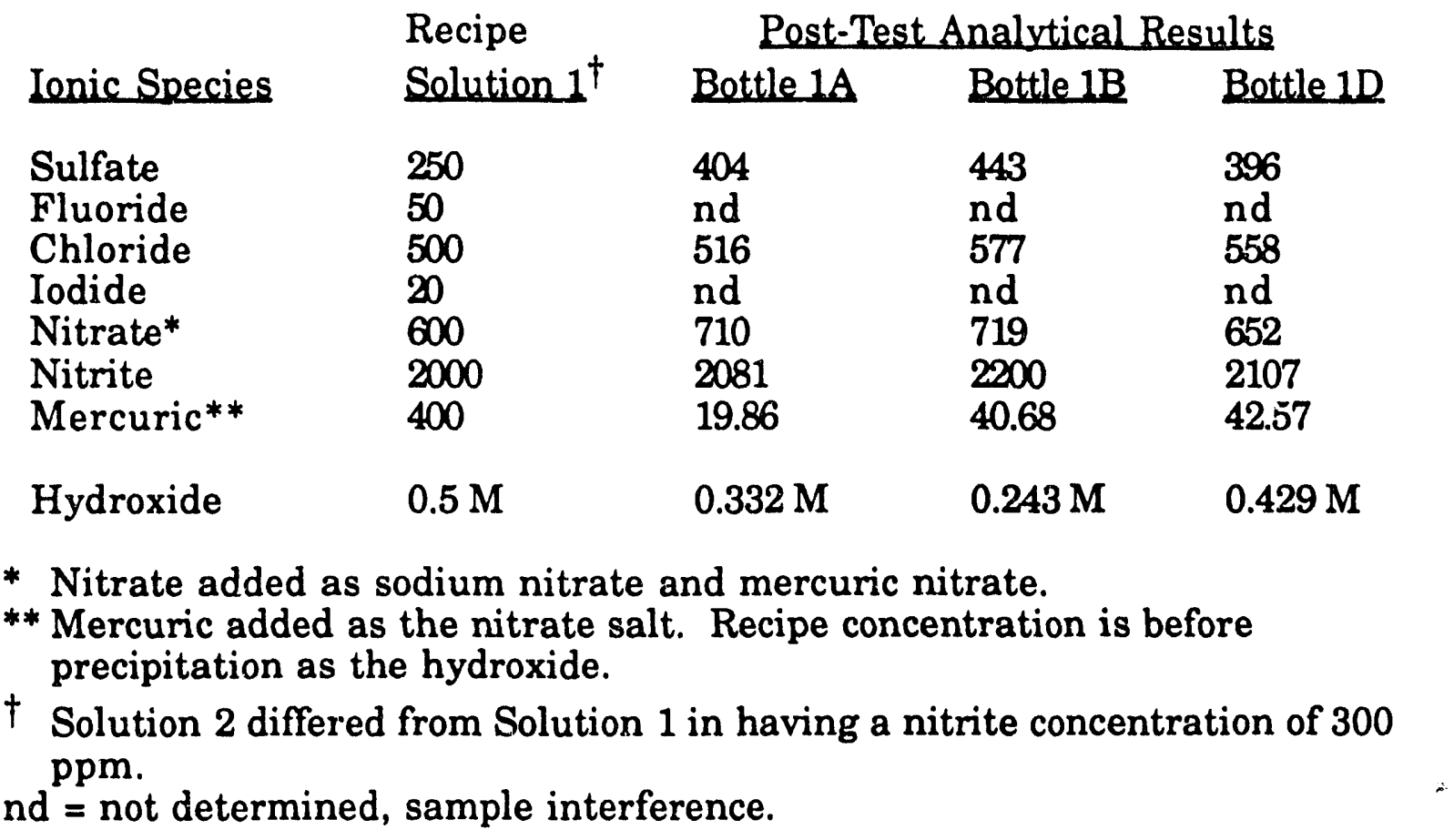

TABLE II.

Results Of Inspection Of Tested Coupons

Bottle No. Solution

$\begin{array}{ll}\text { 1A } & 1 \\ \text { IB } & 1 \\ \text { IC } & 1 \\ \text { ID } & 1 \\ \text { IE } & 1 \\ \text { IF } & 1 \\ \text { 2G } & 2\end{array}$

Alloy and Condition

Observations
A537, as-received, polished A537, as-received, polished A537, polished, heat-treated A537, as-received, mill scale $304 \mathrm{~L}$, as-received, polished C276, as-received, polished A537, as-received, polished
Uniform corrosion, No Pits Uniform corrosion, No Pits Uniform corrosion, No Pits Uniform corrosion, No Pits Tarnish, No Pits Stain, No Pits Uniform corrosion, Pits 
WSRC-TR-92-375

UNCLASSIFIED

Page 7 of 10

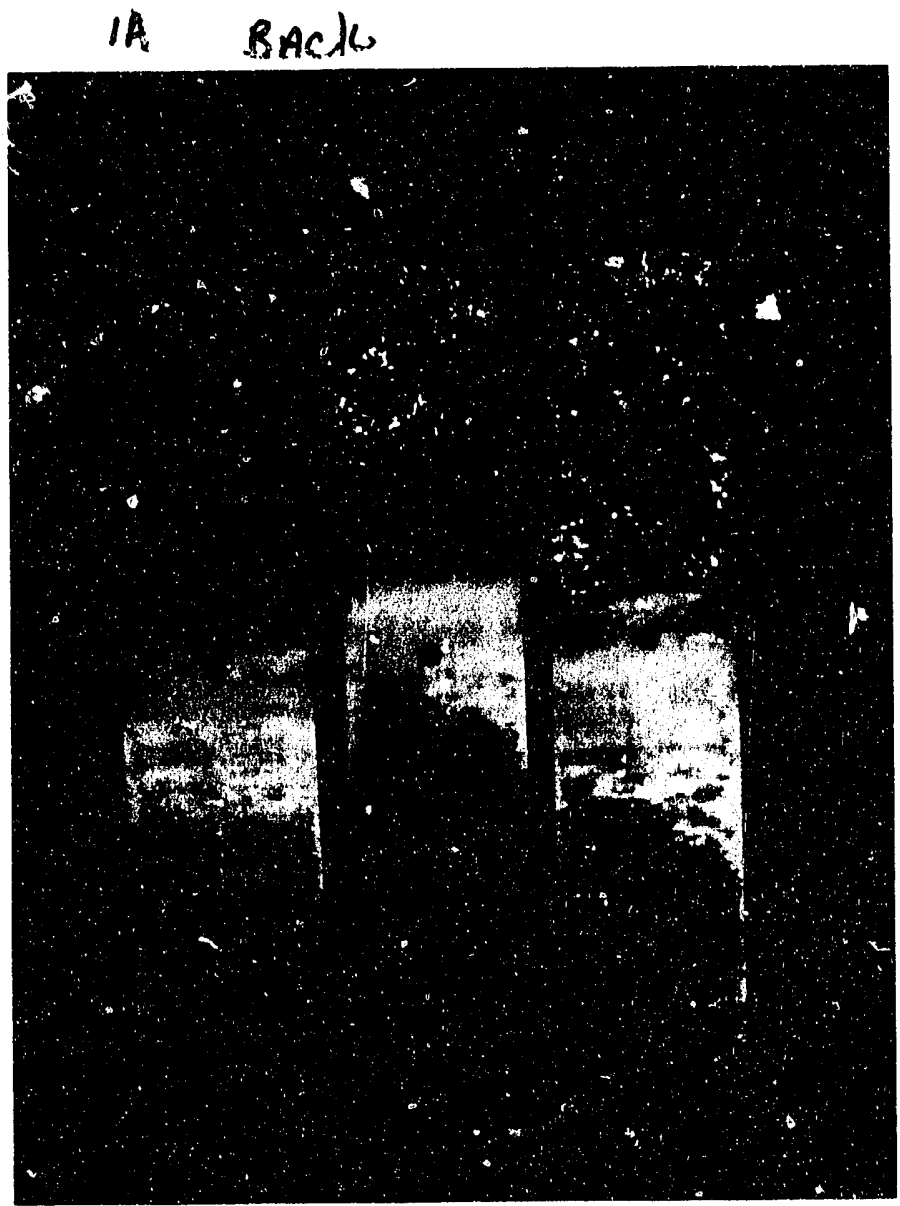

Figure 1. Unirorm Corrosion On The Vapor Space Portion Of A537 Coupons Exposed To Solution 1. 
WSRC-TR-92-375

UNCLASSIFIED

Page 8 of 10

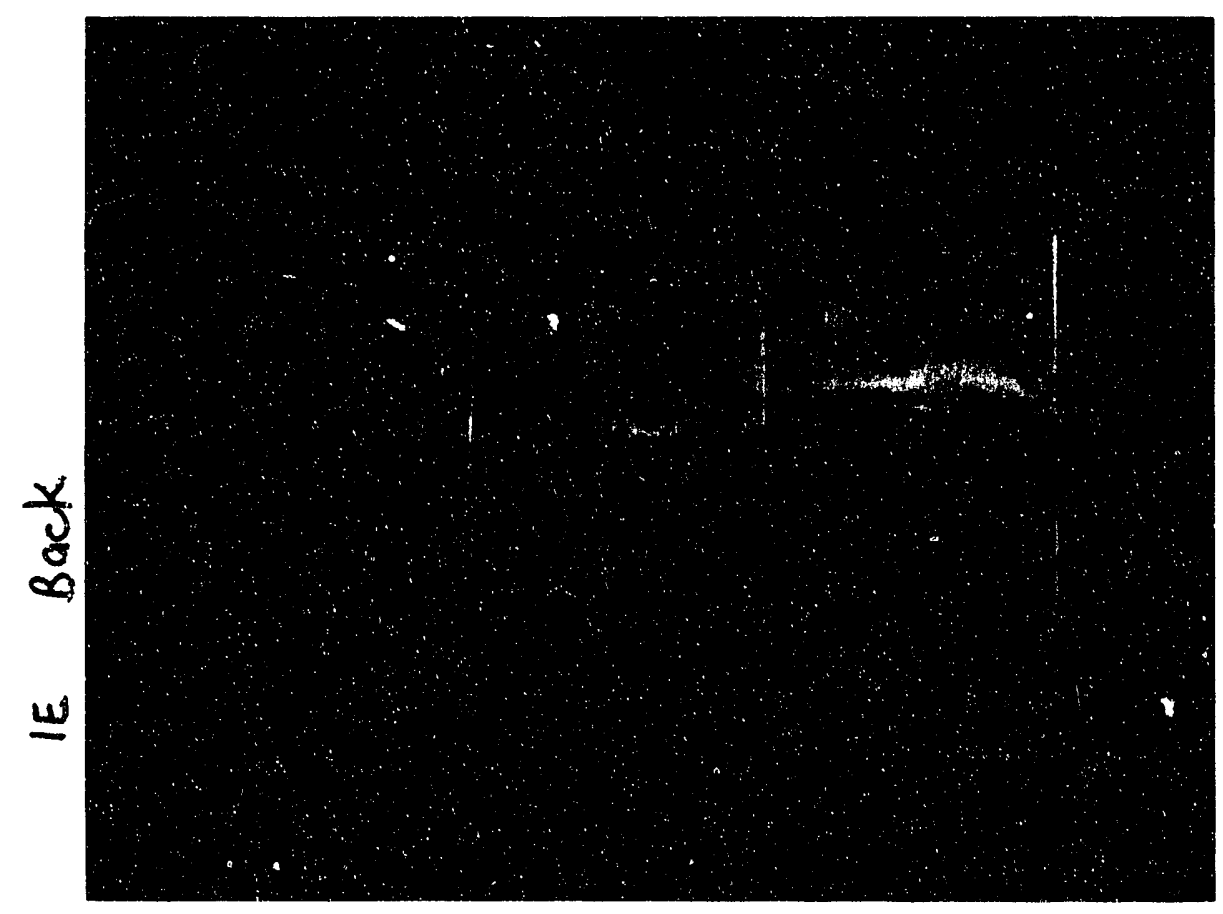

Figure 2. Type 304L Stainless Steel Coupons After Immersion. 
WSRC-TR-92-375

UNCLASSIFIED

Page 9 of 10

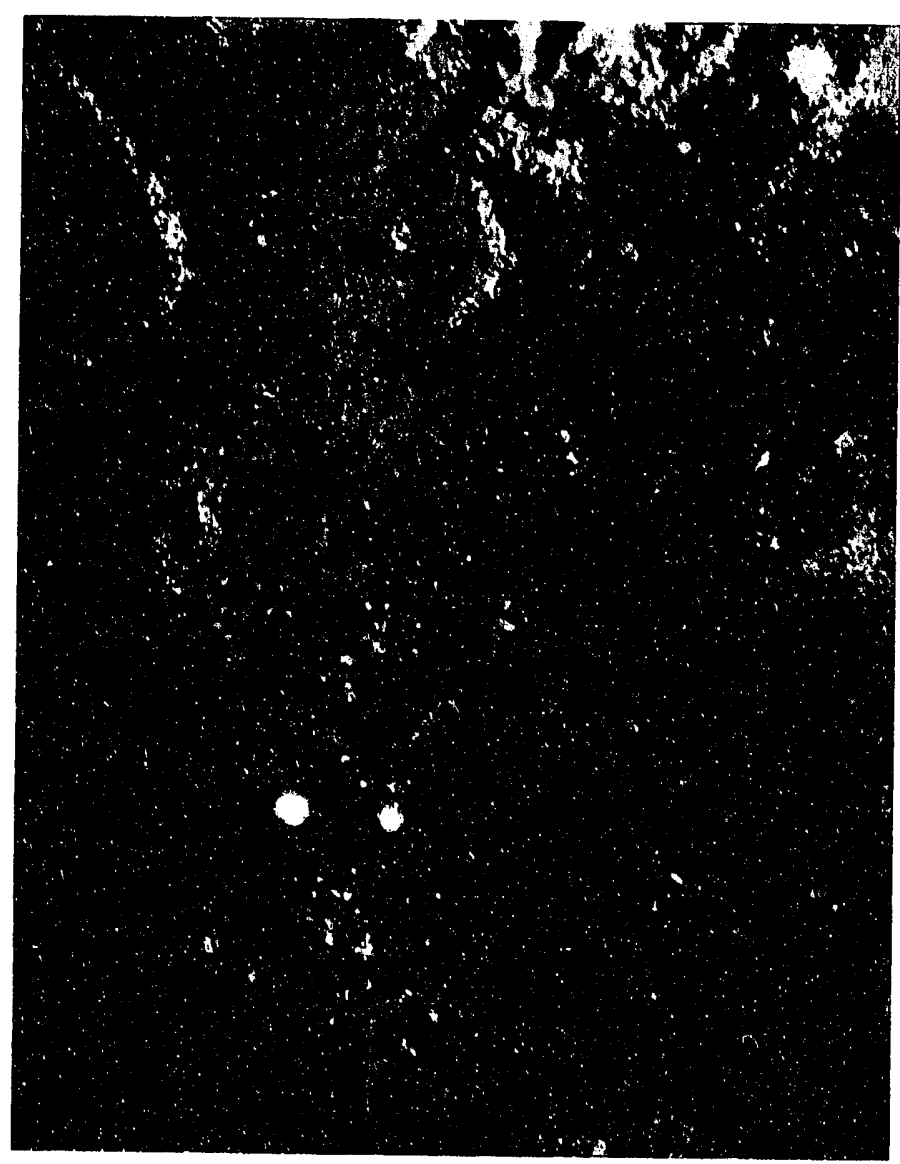

Figure 3. Liquid Mercury Drops And Particulate Deposits On An A537 Coupon (magnification 65X). 


\section{Westinghouse Savannah River Company}

D. L. Fish, 773-A

T. L. Capeletti, 773-41A

E. W. Holtzscheiter, 773-A

J. E. Marra, 773-A

D. B. Amerine, 704-S

J. P. Ortaldo, 704-S

H. H. Elder, 704-S

N. F. Chapman, 704-27S

E. J. Freed, 704-27S

D. H. McGuire, 704-27S

J. E. Owen, TC-S1

J. M. Gillman, 704-27S

J. T. Gee, 704-24S

D. C. Iverson, 704-29s

G. T. Wright, 703-H

B. L. Lewis, 703-H

M. W. Lewis, 703-H

M. C. Chandler, 703-H

T. C. Hsu, 703-H

R. T. Begley, 773-A

J. D. Cohen, 730-A

L. M. Papouchado, 773-A

W. L. Tamosaitis, 773-A

M. R. Louthan, Jr., 773-A

D. T. Rankin, 773-A

E. G. Caveness, 730-A

E. J. Majzlik, 730-A

T. J. French, 730-A

J. T. Carter, 704-1T

L. F. Landon, 704-T

R. A. Jacobs, 704-1T

M. J. Plodinec, 773-A

D. F. Bickford, 773-A

G. T. Chandler, 773-A

D. T. Hobbs, 773-A
C. F. Jenkins, 730-A

K. J. Imrich, 730-A

F. M. Heckendorn, II, 773-A

J. I. Mickalonis, 773-A

B. J. Wiersma, 773-A

P. E. Zapp, 773-A (3)

MTS Records (5)

(c/0 L. K. Summers, 773-A)

SRTC Document Control, 773-A (4) 

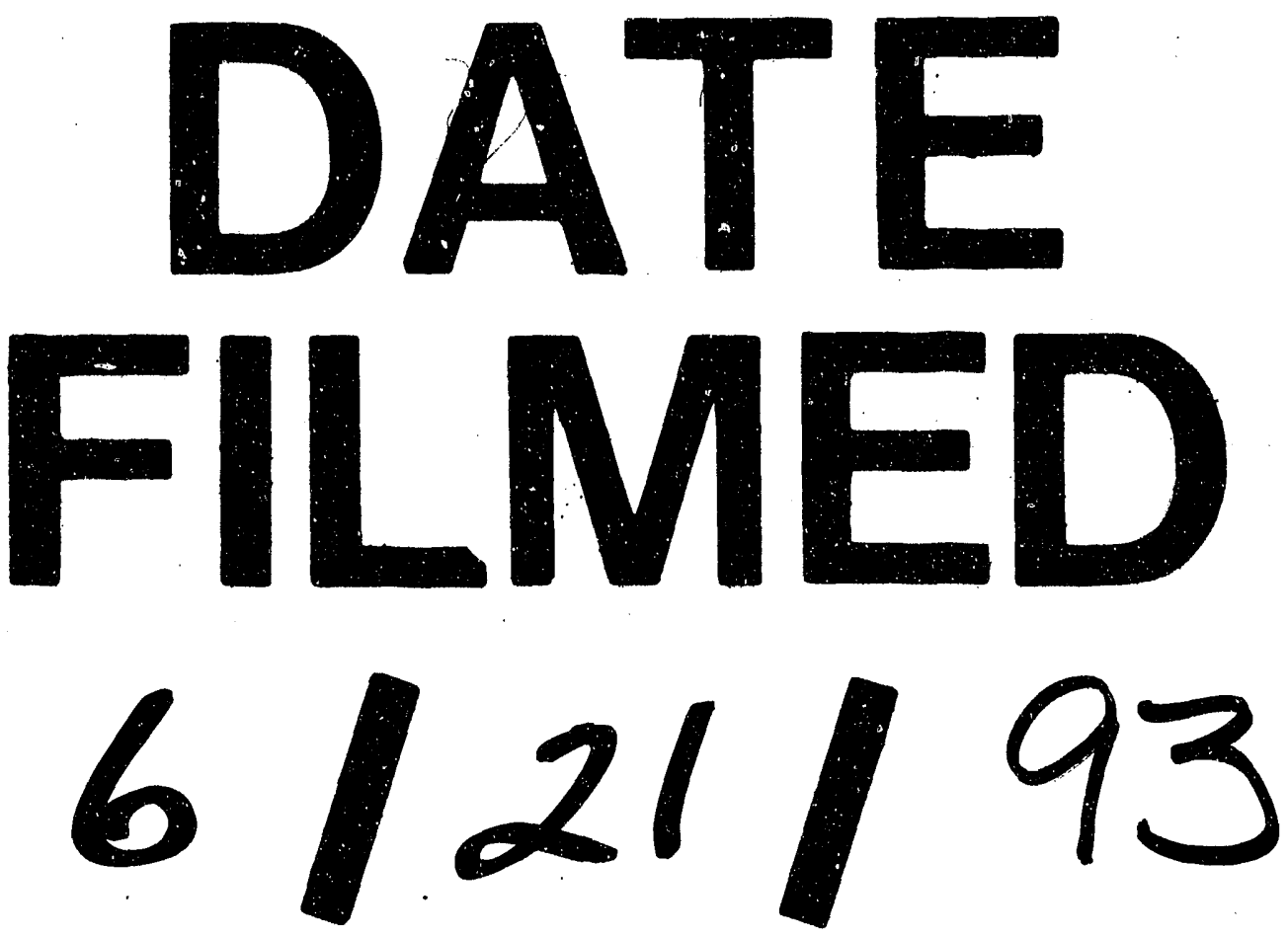
